\title{
A VUELTAS CON LA PROGRESIÓN NARRATIVA EN LA LÍRICA GALLEGO-PORTUGUESA. ¿UNA SECUENCIA EN LAS CANTIGAS DE SANCHO SANCHEZ, CLERIGO?*
}

\author{
Miguel Ángel Pousada Cruz \\ miguelangel.pousada@usc.es \\ Universidad de Santiago de Compostela
}

Los folios 200v-201v del Cancioneiro da Biblioteca Nacional de Lisboa $(=B)$ y $83 \mathrm{v}-84 \mathrm{r}$ del Cancioneiro da Biblioteca Vaticana $(=V)$ conservaron copia de un pequeño conjunto de cantigas que, conforme a las rúbricas atributivas y a la Tavola colocciana $(=C)$, es de la autoría del trovador Sancho Sanchez, clérigo ${ }^{1}$.

El objetivo de este estudio no es otro que el de analizar la existencia de un posible macrotexto -i. e., secuencia (lírico-)narrativa o progresión narrativa $-^{2}$ donde se engarzan, desde el punto de vista del

"El presente trabajo se enmarca en las actividades de los proyectos de investigación Lírica Profana Galego-Portuguesa, incluido dentro del Arquivo Galicia Medieval del Centro Ramón Piñeiro para a Investigación en Humanidades, financiado por la Xunta de Galicia, y La expresión de las emociones en la lírica románica medieval, subvencionado por el Ministerio de Economía y Competitividad, con referencia FFI2012-37355. Ambos proyectos están coordinados por la Prof. ${ }^{a}$ Mercedes Brea.

${ }^{1}$ Para una aproximación a la biografía de este autor, consúltese, entre otros, Carolina Michaëlis de Vasconcelos, Cancioneiro da Ajuda, Halle a. S., M. Niemeyer, 1904, vol. II, p. 616; António Resende de Oliveira, «Do Cancioneiro da Ajuda ao «Livro das Cantigas» do Conde D. Pedro. Análise do acrescemento à secção das cantigas de amigo de $\omega »$, Revista de História das Ideias, 10 (1988), pp. 750-751; António Resende de Oliveira, Depois do espectáculo trovadoresco. A estrutura dos cancioneiros peninsulares e as recolhas dos século XIII e XIV, Lisboa, Edições Colibri, pp. 435-436; António Resende de Oliveira, Trobadores e xograres, Vigo, Xerais, p. 181; Giuseppe Tavani, A poesía lírica galego-portuguesa [1986], $3^{\mathrm{a}}$ ed., Vigo, Galaxia, 1991, p. 324; Giuseppe Tavani, s. v. «Sancho Sanchez, clérigo», en Giulia Lanciani y Giuseppe Tavani (coords.), Dicionário da Literatura Medieval Galega e Portuguesa, Lisboa, Editorial Caminho, 1993, pp. 603-604; Giuseppe Tavani, Trovadores e jograis. Introdução à poesia medieval galego-portuguesa, Lisboa, Editorial Caminho, 2002, p. 440; y, sobre todo, José António Souto Cabo, «In capella dominis regis, in Ulixbona e outras nótulas trovadorescas», en Antonia Martínez Pérez y Ana Lucia Baquero Escudero (eds.), Estudios de literatura medieval. 25 años de la Asociación Hispánica de Literatura Medieval, Murcia, Universidad de Murcia - Servicio de Publicaciones, 2012, pp. 879-888. Un resumen de los datos biográficos del autor puede ser consultado, también, en Miguel Á. Pousada Cruz, «Las cantigas de Sancho Sanchez, clérigo», Estudios Románicos, 24 (2015), pp. 174-175.

${ }^{2}$ Queremos dejar constancia de que entendemos los términos macrotexto, progresión narrativa, secuencia narrativa y secuencia lírica en el mismo sentido: una secuenciación lógica del contenido de un conjunto de composiciones que forman una unidad lírico-narrativa. Además, queremos destacar que, en nuestro análisis, dicho conjunto secuenciado de composiciones no busca anular el valor (ya filológico, ya literario, ya hermenéutico) de cada uno de los elementos que forman dicha unidad; se pretende, por tanto, proponer un análisis de las cantigas implicadas 
contenido, cada una de las composiciones del cancionero atribuido a este trovador. Esta circunstancia supone, como se verá más adelante, alterar el orden en el que las composiciones han sido transmitidas a través de los apógrafos coloccianos, al menos a la hora de intentar comprender el mensaje en conjunto que pueden encerrar las cantigas que configuran el corpus de este autor. Además, cabe destacar que el contenido de las cinco cantigas de amigo parece estar en relación dialógica con la única composición de amor atribuida al autor. Esta interacción entre ambos géneros alberga, por tanto, las dos posibles visiones de la misma relación afectiva: la perspectiva que tiene la joven -que, como veremos, oscila entre la actitud altiva de la senhor y la transparencia de emociones típica de la amiga- y la manera en la que el amigo percibe la relación amorosa.

\section{El estudio de las Secuencias en la lírica profana gallego- PORTUGUESA}

La idea de que existen grupos de cantigas conectadas desde el punto de vista del contenido se encuentra ya en Friedrich Christian Diez $^{3}$. Al analizar el corpus lírico del rey Don Denis, el padre de la Filología Románica percibió que su Sammlung podía ser dividida en dos grandes secciones y, además, las 51 cantigas que formarían la segunda hacían referencia a «einen und denselben Freund d. h. Liebenden, der ihren Mittelpunkt bildet, und sind fast ohne Ausnahme an Personen gerichtet, gleichsam kleine lyrische Briefe, oder es sind Gespräche». Este conjunto de composiciones formaría una Liebesroman ('novela de amor') donde, sin embargo, los poemas individuales presentarían -según indica Diez- una vaga conexión y faltaría una verdadera conclusión ${ }^{4}$.

Unos años más tarde, Alfred Jeanroy, cuando duda del origen popular de las cantigas gallego-portuguesas, indica que estas «chansons se suivent dans un certain ordre nécessaire, qu'elles forment comme les épisodes de petits romans» ${ }^{5}$.

José Joaquim Nunes, en la introducción a su edición del corpus de las cantigas de amigo, destacó también esa secuencialidad presente en los textos y llegó a afirmar que:

Pela variedade de scenas que nelas se descrevem, as nossas cantigas d'amigo podem comparar-se a uma fita cinematográfica, na qual perpassa tôda a vida dos namorados; o seu primeiro encontro (LXVI),

\footnotetext{
desde el punto de vista de su relación con un todo.

${ }^{3}$ Friedrich Christian Diez, Über die erste portugiesische Kunst- und Hofpoesie, Bonn, bie Eduard Weber, 1863.

${ }^{4}$ Ibidem, p. 97.

${ }^{5}$ Alfred Jeanroy, Les origines de la poésie lyrique en France au Moyen Âge. Études de littérature française et comparée, Paris, Librairie Hachette, 1889, p. 315.
} 
os protestos de amor (CCCCIV, CCCCXXXIII), os costumados arrufos (CXCVI), seguidos de reconciliação (CLXXI, CXCII) e, conforme o costume, de aumento do afecto que os prende, expresso despois em palavras cheias de paixão (CCCXXXII), a saída forçada dêle, donde a dôr da ausência e a saüdade dela (XCIX, CXXXIII, CXL, etc. $)^{6}$.

La proximidad temática entre las composiciones del corpus lírico gallego-portugués, esto es, el hecho de que la narración lírica que se canta sea en cierta manera arquetípica también llevó a Manuel Rodrigues Lapa a escribir que, en las cantigas de amigo, toda «a escala sentimental da vida amorosa da menina nos é comunicada com o mais vivo realismo», por lo que, teniendo presente la totalidad de las composiciones de este género poético-musical, podría llegar a reconstruirse «o romance completo e ideal da namorada» ${ }^{7}$.

Isabel Pope, desde una visión algo diferente, afirmó también que, con frecuencia, las cantigas están unidas en grupos bajo una misma idea o a través de la descripción de un lugar o de un escenario particular. Las composiciones de un autor concreto formarían ciclos en los que el trovador compondría todas las posibles variaciones de un tema concreto, si bien no habría ningún tipo de «narrative or dramatic development in the poems of such cycle»; Pope entiende, por tanto, que esas composiciones serían diferentes expresiones de un mismo «thought, emotion, or setting» ${ }^{8}$.

Uno de los autores que más ha profundizado sobre esta línea de estudio ha sido Giuseppe Tavani. Para el investigador italiano, la poesía gallego-portuguesa, dentro de su característico isomorfismo de género,

presenta anche casi più particolari di congruenza intertestuale, dimostrati da insiemi ristretti di testi di uno stesso autore che possono sia iscriversi - con una propria specificità semantica- entro il singolo macrotesto costituito da uno dei tre generi principali, sia partecipare di più d'uno di codesti generi'.

${ }^{6}$ José Joaquim Nunes, Cantigas d'amigo dos trovadores galego-portugueses. Edição crítica acompanhada de introdução, comentário, variantes e glossário, Coimbra, Imprensa da Universidade de Coimbra, 1926-1928, vol. I: «Introdução» (1928), pp. 9-10.

${ }^{7}$ Manuel Rodrigues Lapa, Lições de literatura portuguesa: época medieval [1934], $10^{\mathrm{a}} \mathrm{ed}$., [Coimbra], Coimbra Editora, 1981, p. 167.

${ }^{8}$ Isabel Pope, «Medieval Latin Background in the Thirteenth-Century Galician Lyrics», Speculum, vol. IX/1 (1934), pp. 3-25 [p. 4].

${ }^{9}$ Giuseppe Tavani, «La poesia lirica galego-portoghese», en Erich Köhler, Ulrich Mölk, Dietmar Rieger (dirs.), Grundriss der romanischen Literaturen des Mittelalters, Heidelberg, C. Winter - Universitätsverlag, 1980, vol. II: «Les genres lyriques», tomo 1, fasc. 6/C, pp. 58-61 [p. 58]. Nótese que esta información fue posteriormente recogida en Giuseppe Tavani, A poesía lírica galego-portuguesa, op. cit., pp. 100-104 [pp. 100-101] y Giuseppe Tavani, Trovadores e jograis. Introdução à poesia medieval galego-portuguesa, Lisboa, Editorial Caminho, 2002, pp. 152-157 [pp. 152-153]. 
Esos grupos de textos coincidirían con «brevi canzonieretti individuali» que, a pesar de su múltiple apariencia superficial, permitirían ver «una sostanziale univocità semantica». Entre los ejemplos aducidos por este investigador, aparecen citadas las siete cantigas del corpus lírico del juglar Martin Codax ${ }^{10}$, las ocho cantigas del trovador Johan Nunez Camanez ${ }^{11}$ y el cancionero del trovador Fernan Velho ${ }^{12}$. Además, considera que la «acentuada serielidade» sería uno de los rasgos más característicos de las cantigas de amigo paralelísticas, ya que este tipo de composiciones parecen distribuirse en series orgánicas de textos

coordinati in un unico discorso poetico, più o meno complesso, più o meno coerente, più o meno articolato; un discorso che può svilupparsi linearmente, con andamento pressoché narrativo, o che può invece avvolgersi spiralmente su se stesso, o ancora che si organizza in sezioni concentricamente disposte e sovrapposte in dissolvenza; comunque sempre un discorso unico, nel quale le singole poesie assumono la funzione di elementi costitutivi di un testo più ampio, coincidente con la serie ${ }^{13}$.

La tendencia narrativa de las cantigas gallego-portuguesas fue analizada por extenso en una monografía de Francisco Nodar Man$\mathrm{so}^{14}$. Para este autor, que sigue la senda de otros críticos como Xosé Filgueira Valverde ${ }^{15}$, una cantiga es «un enigma cuya solución exige un laberinto de posibilidades contradictorias»; los datos que omite

${ }^{10} \mathrm{El}$ corpus lírico atribuido a Martin Codax está formado por siete composiciones: 91,1 (N4/B1281/V887), 91,2 (N7/B1284/V890), 91,3 (N6/B1283/V889), 91,4 (N2/B1279/V885), 91,5 (N3/B1280/V886), 91,6 (N1/B1278/V884) y 91,7 (N5/B1282/V888). Todas las numeraciones de las composiciones mencionadas en este trabajo remiten a MedDB2 - Base de datos da lírica profana galego-portuguesa, versión 2.3.3, del Centro Ramón Piñeiro para a Investigación en Humanidades [accesible desde < http://www.cirp.es/pls/bdo2/f?p=MEDDB2>]. Del mismo modo, los nombres de los autores son reproducidos con la forma gráfica allí empleada.

${ }^{11}$ El corpus lírico atribuido a Johan Nunez Camanez está formado por ocho composiciones: 74,1 (A111/B224), 74,2 (B654/V255), 74,3 (A112/B225), 74,4 (B653/V254), 74,5 (B655/ V256), 74,6 (A113/B226), 74,7 (B651/V252) y 74,8 (B652/V253).

${ }^{12}$ El corpus lírico atribuido a Fernan Velho está formado por doce composiciones: 50,1 (A260/B437/V49), 50,2 (B1504), 50,3 (A264/B441/V53), 50,4 (A262/B439/V51), 50,5 (V404), 50,6 (A261/B438/V50), 50,7 (A257/B434/V46), 50,8 (B442/V54), 50,9 (A258/B435/ V47), 50,10 (A263/B440/V52), 50,11 (A259/B436/V48) y 50,12 (B819/V403).

${ }^{13}$ Giuseppe Tavani, «Parallelismo e iterazione. Appunti in margine al criterio di pertenenza», Cultura Neolatina, desde el vol. XXXIII (1973), pp. 9-32 [p. 25]. Nótese que esta información fue posteriormente recogida en Giuseppe Tavani, «Paralelismo e iteração. À margem do critério jakobsoniano de pertinência: a propósito das cantigas de Martín Codax»; en Giuseppe Tavani, Poesia e ritmo, Lisboa, Livraria Sá da Costa Editora, 1983, pp. 143-164 [p. 154] y en Giuseppe Tavani, «Martin Codax e o seu cancioneiro», en Giuseppe Tavani, Ensaios portugueses. Filologia e Linguistica, Lisboa, Imprensa Nacional-Casa da Moeda, 1988, pp. 265-313 [p. 305].

${ }^{14}$ Francisco Nodar Manso, La narratividad de la Poesía lírica galaico-portuguesa. Estudio analitico, Kassel, Edition Reichenberger, 1985.

${ }^{15}$ Ibidem, p. 107. 
una cantiga se detallan en otra(s) y, por tanto, esa «mutua complementación desemboca inevitablemente en lo narrativo» ${ }^{16}$. Esta opinión no es compartida por completo por todos los autores, ya que los vacíos que existen entre los componentes de una supuesta secuencia solo pueden ser subsanables a través de la interpretación subjetiva de un lector individual ${ }^{17}$, algo que dificulta, en última instancia, la identificación de todos esos textos relacionados entre sí.

Tres años más tarde del lanzamiento de la anterior monografía, Julian Weiss publica su artículo sobre las secuencias líricas en las cantigas de amigo. El trabajo marca un antes y un después a la hora de estudiar esta cuestión dentro de la lírica trovadoresca peninsular, ya que, además de realizar un completo estado del arte y de analizar, dentro del cancionero del trovador Johan Mendiz de Briteiros ${ }^{18}$, una secuencia lírica formada por tres cantigas de amigo $(73,1,73,2$ y $73,5)$, que está basada sobre el «theme of the dream love» ${ }^{19}$, sitúa este fenómeno en relación con el contexto literario medieval euro$\mathrm{peo}^{20}$. En un último epígrafe recoge, además, las secuencias que el autor ha registrado de entre las diferentes ediciones y trabajos previos realizados por otros investigadores, analizando la pertinencia (o no) de las mismas ${ }^{21}$.

Weiss, siguiendo la estela dejada por trabajos previos -como los estudios ya citados de Tavani- destaca que las secuencias están normalmente formadas por cantigas de amigo, aunque señala que algunos críticos también registran grupos narrativos de cantigas de amor o incluso conjuntos formados por composiciones de ambos géneros. Además, recuerda que la temática tratada abarca todas las situaciones existentes para la canción trovadoresca gallego-portuguesa $-\ll$ the girl's confrontation with her mother or guardian, the meeting or parting of lovers, the rendezvous at a sanctuary, and so on»-y que los trovadores a los que se les atribuye alguna secuencia no se circunscriben a un entorno particular ni a un tiempo concreto ${ }^{22}$. Sin embargo, el investigador británico expresa con rotundidad que, debido a la subjetividad, esta cuestión es muy controvertida. Además, señala que podemos caer en el riesgo de pensar que existen ciertos macrotextos donde simplemente operan los confines léxicos y temáticos de esta escuela trovadoresca $-i$. e., repetición de metáforas, imágenes y símbolos; la iteración de voces líricas; la reaparición de situaciones

\footnotetext{
${ }^{16}$ Francisco Nodar Manso, op. cit., p. 106. p. 106.

${ }^{17}$ Julian Weiss, «Lyric Sequences in the "Cantigas d'amigo"», Bulletin of Hispanic Studies, 65/1 (1988), pp. 21-37 [p. 23].

${ }^{18}$ El corpus lírico atribuido a Johan Mendiz de Breteiros está formado por nueve composiciones: 73,1 (B864/V450), 73,2 (B865/V451), 73,3 (B861/V447), 73,4 (B863/V449), 73,5 (B866/V452), 73,6 (B862/V448), 73,7 (B860/V446), 73,8 (B859/V445) y 73,9 (B867/V453).

${ }^{19}$ Julian Weiss, art. cit., p. 28.

${ }^{20}$ Ibidem' pp. 22-23.

${ }^{21}$ Ibidem, pp. 32-35.

${ }^{22}$ Ibidem, p. 22.
} 
concretas, etc.-, algo que podría llevar a identificaciones erróneas. El autor recuerda, también, dos importantes cuestiones: en primer lugar, el orden de las composiciones de la secuencia no tendría que coincidir con el que presentan dichas composiciones en los manuscritos (y el papel del trovador o del compilador a este respecto); la segunda, el hecho de que no debería ser asumido tan a la ligera que la posible ligación entre composiciones implicase que los textos hubiesen sido escritos para ser interpretados o leídos siguiendo la coherencia líriconarrativa del macrotexto concreto ${ }^{23}$, algo que sí contemplan Vicenç Beltran ${ }^{24}$ y Henrique Monteagudo ${ }^{25}$. Weiss concluye:

In short, the grouping together of poems to form brief lyrics sequences, whether carried out by composer or compiler, appears to have been common practice in the Galician-Portuguese school. However, as I have suggested, its precise scope will always be a matter of subjective interpretation, and because of this, future research will have to be undertaken with a good deal more caution than has been the case to date $^{26}$.

Diez años más tarde, en una postura que parece estar a medio camino entre la aceptación y el rechazo de tales engarces narrativos, Xosé Ramón Pena, al hablar sobre el ciclo do mar de Vigo ${ }^{27}$, señala que pueden encontrarse «seriacións que semellarían responder a unha certa lóxica narrativa». No obstante, en caso de aceptar como ciertas dichas series, se trataría «dun macrotexto lírico e no que cada un dos poemas mantén a potencialidade suficiente para encabezar ou resumir a suposta novela de amor que o xograr nos quixo transmitir» ${ }^{28}$.

Dentro del corpus de amigo, podemos encontrar un grupo de composiciones en las que la acción amorosa que se canta se desarrolla en el marco de un santuario, en el contexto de una peregrinación a una romería: son las conocidas como cantigas de santuario. Tal y como recuerda Giuseppe Tavani, «il motivo del pellegrinaggio risulta, il più delle volte, puro pretesto poetico per l'incontro con l'amante,

${ }^{23}$ Julian Weiss, art. cit., p. 23.

${ }^{24}$ Vicenç Beltran, «Martin Codax o el poeta intemporal», Alacant, Biblioteca Virtual Cervantes, 2003 [consultable en línea, <http://www.cervantesvirtual.com/nd/ark:/59851/ bmcjh3g1>, 12/2014]: «La elevada recurrencia de formas y motivos en sus siete cantigas, probablemente seriadas y destinadas a ser juzgadas conjuntamente, ha impedido que ninguna de ellas destaque por su impacto singular, como la cantiga de Mendinho o la conocida de Torneol».

${ }^{25}$ Henrique Monteagudo, "Cantores de santuario, cantares de romaría», en $O$ Mar das Cantigas. Actas do congreso, Santiago de Compostela, Xunta de Galicia, 1998, pp. 95-123: «Seguramente, a articulación en serie implicaba tamén a execución das cantigas en secuencia continuada», p. 107.

${ }^{26}$ Julian Weiss, art. cit., p. 25.

${ }^{27}$ Xosé Ramón Pena, «O ciclo do mar de Vigo: propostas de lectura para un novo milenio», en $O$ Mar das Cantigas. Actas do congreso, op. cit., pp. 73-79.

${ }^{28} \mathrm{Ibidem}$, p. 77. Un poco más adelante daremos cuenta de algunos investigadores que niegan la existencia de estas secuencias líricas. 
elemento volutamente ingenuo e «popolaristico» indotto nella tessitura lirica della cantiga d'amigo» ${ }^{29}$. Traemos a colación este grupo de composiciones porque, desde sus primeros análisis en conjunto ${ }^{30}$, siempre se les ha atribuido, además de una homogeneidad temática característica que las relaciona, un importante carácter serial ${ }^{31}$. De este modo, Henrique Monteagudo señala que

é rotundamente favorable a considerar que por vía da regra as cantigas de santuario de cada autor forman serie. Endebén, convén deixar claro que cando falamos da articulación nunha serie non estamos a pensar necesariamente nunha secuencia rixidamente encadeada nin nunha narración linealmente ordenada (aínda que o elemento narrativo adoita estar presente, mesmo nalgunha ocasión organizado cunha lóxica lineal), senón en interrelacións frouxas, fundadas na recorrencia de motivos e de formas. Seguramente, a articulación en serie implicaba tamén a execución das cantigas en secuencia continuada. Por outra banda, se admitimos a articulación en serie, hai que ter en conta a posibilidade de que nalgunha serie de cantigas de romaría se incluísen textos que non presentan a configuración típica destas, isto é, carentes de calquera marca de modalidade. O caso máis discutido é, claro está, o de Martin Codax, pero non imos agora deternos nel, pois o seu cancioneiro é claramente anómalo desde o punto de vista da cantiga de santuario. Afonso Lopez de Baian, sen ser un autor típico de cantigas de santuario, ofrece un caso interesante para a discusión, e na nosa opinión bastante claramente favorable á hipótese da 'serialidade ${ }^{{ }^{332}}$.

${ }^{29}$ Giuseppe Tavani, cap. cit., pp. 88-89 [p. 88]. Esta información aparece después recogida en Giuseppe Tavani, op. cit., 1991, pp. 142-143 [p. 142] y en Giuseppe Tavani, op. cit., 2002, pp. 199-200 [p. 199].

${ }^{30}$ Entre otros, Xosé Filgueira Valverde, «Poesía de santuarios», Compostellanum, III/4 (1958), pp. 639-654; Mercedes Brea, «Las "Cantigas de Romería” de los Juglares Gallegos», en Santiago Fortuño Llorens y Tomàs Martínez Romero (eds.), Actes del VII Congrés de l'Assossiació Hispànica de Literatura Medieval (Castelló de la Plana, 22-26 de setembre de 1997), Castelló de la Plana, Publicacions de la Universitat Jaume I, 1999, vol. I, pp. 381-396; Ângela Correia, «Sobre a especificidade da cantiga de romaria», Revista da Biblioteca Nacional, vol. 8/2 (1993), pp. 7-22; Mercedes Brea y Pilar Lorenzo Gradín, A cantiga de amigo, Vigo, Edicións Xerais, 1998, p. 261; Pilar Lorenzo Gradín, «A transmisión das cantigas de romaría dos xograres galegos», en $O$ Mar das Cantigas. Actas do congreso, op. cit., pp. 155-168; Henrique Monteagudo, cap. cit., pp. 95-123; y Santiago Gutiérrez García, «Las cantigas de santuario y la peregrinación de Sancho IV a Santiago», en Mercedes Brea (coord.), Pola melhor dona de quantas fez nostro Senhor. Homenaxe á Profesora Giulia Lanciani, Santiago de Compostela, Xunta de Galicia, 2009, pp. 277-290.

${ }^{31}$ Xosé Filgueira Valverde, art. cit., pp. 639-654: «Las canciones en serie y de tipo ingenuo, adscritas a romerías, forman, es cierto, un conjunto superior a todos los demás temas "de amigo" en número y en calidad», p. 645; «A. Correia y X. Filgueira Valverde coinciden en señalar una cierta coherencia interna en este grupo de composiciones», Mercedes Brea, cap. cit., p. 392.

${ }^{32}$ Henrique Monteagudo, cap. cit., p. 107. Para una explicación más extensa sobre Afonso Lopez de Baian, véase Pilar Lorenzo, Don Afonso Lopez de Baian, Cantigas, Alessandria, Edizioni dell'Orso, 2008, p. 66: «La primera cantiga de amor que los testimonios manuscritos atribuyen al autor que nos ocupa (Sennor, que grav'oj'a mi é) revela desde el punto de vista argumental una estrecha dependencia con sus cantigas de amigo, de modo que se puede establecer en su producción amorosa una especie de 'dialogía' en la que ambos géneros se complementan 
Junto a estas reflexiones críticas tomadas de las obras generales o de trabajos específicos de referencia para el estudio de la lírica trovadoresca escrita en el occidente peninsular, es posible encontrar otras menciones en filólogos e historiadores que se han encargado de editar y/o estudiar el corpus lírico atribuido a un autor concreto.

Uno de los debates más importantes sobre la cuestión de la existencia de secuencias se produjo a raíz de la publicación que daba cuenta del descubrimiento del pergamino Vindel en el mes de febrero del año 1914. Algunos críticos entendieron, una vez analizado este Liederblatt, que las cantigas de amigo, atribuidas al juglar Martin Codax y conservadas -además de en $B$ y $V$ - en esta hoja suelta, formaban parte de una secuencia lírico-narrativa o de un macrotexto poético que solo era comprensible teniendo presentes las composiciones en conjunto. No resultan extrañas, por tanto, las palabras del académico gallego Eladio Oviedo Arce, en su análisis por entregas de la obra del mencionado juglar, cuando indicó que Teodosio Vesteiro Torres ${ }^{33}$ ya había señalado la idea de que las siete cantigas del pergamino «debían considerarse como una sola, por ser uno el asunto de todas ellas» y que, por tanto, esa idea podría ser el motivo por el cual el librero Pedro Vindel, amigo del Prof. Said Armesto -investigador que conocía, según indica Oviedo, el citado trabajo de Vesteiro-, habría subtitulado su edición de las cantigas del pergamino trecentista como «poema musical»»

En torno a la idea de Vesteiro Torres, los investigadores de aquel momento fueron alineándose a favor o en contra. Entre las voces que se alzaron sobre la no existencia de dicha progresión, hay que destacar la de la ilustre filóloga Carolina Michaëlis de Vasconcelos, quien, en su reseña a la edición de Vindel, destaca que «Contra a classificação das Sete Cantigas como poema levanto a objecção que elas são scenas isoladas, e não de evolução progressiva: episódios da vida de uma menina que vivia perto de Vigo. E simultaneamente da vida do jogral $»^{35}$.

Otros investigadores se posicionaron a favor de esta continuidad temática; algunos, como Oviedo Arce, hasta el punto de proponer para la secuencia de Codax el título de «La Enamorada de Vigo»».

desde un punto de vista semántico».

${ }^{33}$ Teodosio Vesteiro Torres, «Martin Codax», en Valentín L. Carvajal (dir.), El Heraldo Gallego, Año III, n. ${ }^{\circ} 147$ (7 de junio de 1876), pp. 345-348. En la p. 347, Vesteiro sugiere que «Estas siete canciones parece que en rigor deben ser una sola, ya que es uno el asunto, por más que las estrofas presenten variadas muestras de la antigua maestría mayor y maestría menor».

${ }^{34}$ Eladio Oviedo Arce, «El Genuino 'Martin Codax', trovador gallego del siglo XIII - Texto literario y musical (continuación)», Boletín da Real Academia Galega, n. ${ }^{\circ} 113$ (enero de 1917), p. 124.

${ }^{35}$ Carolina Michaëlis de Vasconcelos, «A proposito de Martim Codax e as suas cantigas de amor», Revista de Filología Española, tomo II (1915), p. 273.

${ }^{36}$ Eladio Oviedo Arce, art. cit., p. 125. Unas líneas previas, en la p. 124, el autor justifica así la senda iniciada por Vesteiro Torres: «A mi juicio está equivocada la ilustre romanista portuguesa. Creo, con Vesteiro Torres, que las Cántigas Codacianas, consideradas -como aquí se 
Además, indicó, con rotundidad, que no sería esta una singularidad de Codax, puesto que «Nuno Fernandez», «D. Juan Méndez de Briteyros» (sic) y «Payo Gómez Charino» (sic), entre otros, también son -según indica el autor- «poemógrafos» ${ }^{37}$.

Uno de los trabajos más importantes sobre el cancionero de Martin Codax fue publicado por Giuseppe Tavani ${ }^{38}$, en respuesta al conocido artículo de Roman Jakobson ${ }^{39}$-reeditado, tal y como señala Vicenç Beltran ${ }^{40}$, repetidamente-, en el que analizó el corpus lírico del juglar desde un punto de vista puramente estructuralista, y otro de la Prof. ${ }^{a}$ Barbara Spaggiari ${ }^{41}$, en el que editó y analizó minuciosamente el corpus de Martin Codax. En el trabajo del investigador italiano se indica que estas cantigas de amigo paralelísticas deben leerse como un discurso único, ya que la «sucesión serial» es «coerente e completa»; el autor considera que podría tratarse de «un "canto dell'attesa delusa" $[\ldots]$ articolato in sette cantigas d'amigo che in effetti si presentano como altrettante "strofes" (tutte necessarie e sufficienti per istituire un "significato" globale) di un unico "testo"»"

Del mismo modo que ya habían hecho Vesteiro Torres, Oviedo Arce o Tavani, Manuel Pedro Ferreira, en su edición y estudio del pergamino Vindel, reconoce también que «o que mais impressiona nestas cantigas é a sua concepção unitária nos termos da dispositio retórica», ya que el «reportório codaxiano patenteia portanto uma formação retórica não só no que respeita ao texto como no que se refere à música», hasta el punto de poder afirmar que la «unidade

consideran- desde el punto de vista literario, están trabadas por estrechísima unidad temática que, en rigurosa gradación, se desenvuelve progresivamente a través de las siete, como si en efecto, se propusiera el trovador componer un pequeño poema».

${ }^{37}$ Ibidem, pp. 124-125.

${ }^{38}$ Giuseppe Tavani, art. cit., pp. 9-32.

${ }^{39}$ Roman Jakobson, «Carta a Haraldo de Campos sobre a textura poética de Martin Codax», Grial, vol. XXXIV (1971), pp. 392-398.

${ }^{40}$ Vicenç Beltran, art. cit.

${ }^{41}$ Barbara Spaggiari, «Il canzoniere di Martim Codax», Studi Medievali, vol. XXI/I (1980), pp. 367-409. En las páginas 379-380, la profesora italiana dejaba constancia de que «È opinione diffusa che le poesie, nell'ordine in cui ci sono state tramandate, costituiscano la cronostoria di vicende amorose realmene accadute; a nostro avviso rispecchiamo invece un criterio esterno e non cronologico di disposizione, perché non è certo casuale che alternino rigorosamente cantigas di quattro e sei strofi (eccetto l'ultima, di soli due distici, spuria -come vedremo)».

${ }^{42}$ Giuseppe Tavani, art. cit., p. 28. Esta información fue después recogida en Giuseppe Tavani, cap. cit., 1983, 156-157; en Giuseppe Tavani, cap. cit., 1988, pp. 308-309; y en Giuseppe Tavani, art. cit. 2012, pp. 115-116. Recogemos, a continuación, el orden propuesto por este investigador: a) 91,6 (N1/B1278/V884): la protagonista invoca a las olas y al amigo que está en tierras lejanas; b) 91,4 (N2/B1279/V885): después de recibir el mandado del amigo, se dispone a ir a Vigo; c) 91,5 (N3/B1280/V886): solicita a la hermana y a la madre que la acompañen; d) 91,1 (N4/B1281/V887): la protagonista va sola al encuentro de su amigo; e) 91,7 (N5/B1282/ V888): la joven invoca a todas las enamoradas para que la acompañen en su espera; f) 91,3 (N6/B1283/V889): baila en el atrio de la iglesia de Vigo, donde se habría producido el primer encuentro; y finalmente, g) 91,2 (N7/B1284/V890): la protagonista, desesperada, realiza una nueva invocación a las olas ante el retraso de su amado. 
intrínseca do cancioneiro codaxiano é especialmente evidente nas primeiras seis cantigas $\rangle^{43}$.

Frente a estas propuestas, el profesor Camilo Flores muestra una postura contraria a aquellas que establecían una ordenación concreta de las cantigas codacianas. En su razonamiento, parte de la base de que la «constructio lógica y racional, temática», tal como la concebimos en la actualidad, no existe en la lírica trovadoresca. Además, insiste en el error de la crítica tradicional cuando interpreta en las composiciones medievales «un biografismo y una sinceridad que en nada se corresponden con la mentalidad medieval $\rangle^{44}$.

Un trabajo más reciente sobre Martin Codax fue elaborado por Vicenç Beltran. Además de realizar un exhaustivo estado de la cuestión, el investigador catalán incide en los puntos claves que presenta el corpus lírico del juglar y que han sido tratados por la crítica precedente. Entre ellos, según indica, «merece un lugar de honor la probable estructuración narrativa de la secuencia de sus siete cantigas». Además, Beltran enfatiza el hecho de que la intensidad de los elementos de cohesión en el cancionero del autor y la existencia de, por un lado, los testimonios $B$ y $V$, y, por otro, el pergamino Vindel, transforman las cantigas de Martin Codax en un caso paradigmático. Concluye el autor indicando:

A la luz de nuestros conocimientos actuales sobre los cancioneros de autor, estas estructuras macrotextuales resultan del mayor interés pues, junto a otros indicios, suelen figurar en primer plano de los trabajos recientes sobre este problema; y no me cabe la menor duda de que estos ejemplos de la lírica galaico-portuguesa son los más antiguos documentados en toda la Romania ${ }^{45}$.

Junto a los análisis que contemplan únicamente la existencia de secuencias en las cantigas de amigo atribuidas a un autor determinado, cabe destacar la existencia de otros en los que se engarzan cantigas específicas de los otros géneros poético-musicales. Un ejemplo

\footnotetext{
${ }^{43}$ Manuel Pedro Ferreira, O som de Martin Codax. Sobre a dimensão musical da lírica galego-portuguesa (séculos XII-XIV), Lisboa, Unisys / Imprensa Nacional - Casa da Moeda, 1986, pp. 179-182 [p. 179].

${ }^{44}$ Camilo Flores, s. v. «Martín Codax», Gran Enciclopedia Gallega, Santiago de Compostela - Gijón, Silverio Cañada Editor, tomo XX (1974), pp. 138-140 [p. 138]. Este mismo posicionamiento fue seguido en Antonio Fernández Guiadanes, Fernando Magán Abelleira, Ignacio Rodiño Caramés, María Rodríguez Castaño, Xosé Xabier Ron Fernández y María del Carmen Vázquez Pacho, Cantigas do Mar de Vigo. Edición crítica das cantigas de Meendinho, Johan de Cangas e Martin Codax, Santiago de Compostela, CRPIH, 1998, pp. 10-12 [p. 11].

${ }^{45}$ Vicenç Beltran, art. cit. Esta idea final del texto de Beltran también es defendida en Rip Cohen, 500 Cantigas d'Amigo, Porto, Campo das Letras, 2003, p. 53, cuando dice que si las macrosecuencias «existem - e acredito que possa ser demonstrado que sim - estas seriam as primeiras sequências de cantigas amorosas em qualquer língua vernácula na história da literatura europeia, providenciando uma oportunidade única para estudar a evolução de uma forma de arte lírico-dramática a partir das suas partes constituintes, algo com que Aristóteles aparentemente apenas podia sonhar».
} 
de esto se encuentra en Francisco Nodar Manso ${ }^{46}$, quien, al estudiar un grupo concreto de cantigas de escarnho e maldizer de Alfonso $\mathrm{X}$, señala que «al relacionar las canciones cuyas situaciones temáticas sean semejantes, brotan unidades narrativas que en el fondo son esbozos de breves episodios dramatizables; como sucede en la obra burlesca atribuida a Alfonso X, en la que subyacen varios núcleos narrativos $\rangle^{47}$. Dejando de lado esta cuestión, por considerar que las unidades narrativas sugeridas por Nodar son ciclo temáticos dentro de las cantigas de escarnho e maldizer, pasamos a analizar a continuación la progresión narrativa que podemos encontrar en el corpus de Sancho Sanchez, clérigo ${ }^{48}$.

\section{2. ¿UNA SECUENCIA EN EL CORPUS DEL TROVADOR SANCho SANCHEZ, CLÉRIGO?}

Como ya se ha señalado al inicio del trabajo, el corpus conservado atribuido a Sancho Sanchez fue transmitido únicamente a través de los apógrafos renacentistas $B$ y $V$. Las rúbricas atributivas y el cotejo de los textos conservados en ambos manuscritos con los datos presentes en la conocida como Tavola colocciana permiten adscribir al clérigo un conjunto de seis composiciones -cinco cantigas de amigo y una cantiga de amor- ${ }^{49}$. Las tablas ${ }^{50}$ que incluimos recogen, de modo de-

\footnotetext{
${ }^{46}$ Francisco Nodar Manso, «El carácter dramático-narrativo del escarnio y maldecir de Alfonso X», Revista canadiense de estudios hispánicos, IX/3 (1985), pp. 405-421.

${ }^{47}$ Ibidem, p. 409.

${ }^{48}$ No queremos cerrar este apartado del trabajo sin citar las siguientes referencias bibliográficas que también analizan la existencia de secuencias en la lírica profana gallego-portuguesa: Rip Cohen, Thirty-two Cantigas d'amigo of the Dom Denis: Typology of a Portuguese Renunciation, Madison, Hispanic Seminary of Medieval Studies, 1987, para quien un conjunto de 32 composiciones de Don Denis «form a macro-poem which is structured as the image of a cantiga. Structural components in this macro-text differ from those in an individual cantiga, to be sure, but it would not be inaccurate to say that within the macro-poem the individual cantiga is roughly equivalent to a verse-unit, and that the "strophes" are of eight cantigas each -thus a macro-poem of four strophes, with eight verses to the strophe» [p. iv]; Andoni Arroyo Pérez, «Una secuencia en Johan Baveca», Revista electrónica Lemir. Literatura Española Medieval y Renacimiento, 7 (2003) [consultable desde <http://parnaseo.uv.es/Lemir/Revista/Revista7/JohanBaveca.htm>, 12/2014]; y, finalmente, Rip Cohen, «Dança Jurídica. I. A poética da sanhuda nas cantigas d'amigo. II. 22 Cantigas d'Amigo de Johan Garcia de Guilhade: vingança de uma sanhuda virtuosa», Colóquio - Letras, 142 (1996), pp. 5-50, donde, al analizar un conjunto de cantigas de amigo de Johan Garcia de Guilhade, advierte la existencia de una «sequência de vinte e duas cantigas possilvelmente organizadas pelo próprio poeta», posibilidad que «seria extensível a muitos outros conjuntos de Cantigas d'Amigo, mesmo que, dada a metodologia e as exigências de prova e argumentação, não haja provas suficientes para a maioria desses conjuntos» [p. 28].

${ }^{49}$ Queremos dejar constancia de que, por haber sido ya estudiado por extenso en otro trabajo (Miguel Á. Pousada Cruz, «A tradición manuscrita das cantigas de Sancho Sanchez, clérigo», en Pilar Lorenzo Gradín y Simone Marcenaro (eds.), El texto medieval: de la edición a la interpretación, Santiago de Compostela, Universidade de Santiago de Compostela - Servizo de Publicacións e Intercambio Científico, 2012, Verba. Anexo 68, pp. 225-247) y por no ser el objeto central del actual análisis, soslayamos todas las cuestiones relacionadas con la tradición manuscrita de este corpus concreto, $v$. gr. los problemas textuales que presentan las cantigas conservadas y que habrían sido originados durante los respectivos procesos de copia.

${ }^{50}$ La transcripción de los versos de incipit fue realizada por el autor siguiendo los criterios
} 
tallado para cada uno de los dos cancioneros renacentistas italianos, información relevante sobre la posición que ocupan las cantigas atribuidas al clérigo dentro de los mismos, así como el género poéticomusical y la modalidad a la que se circunscriben las composiciones.

\begin{tabular}{|l|l|l|l|l|l|}
\hline $\begin{array}{l}\mathrm{n}^{\circ}{ }^{\circ} \text { cantiga } \\
\text { en } M e d D B\end{array}$ & $\begin{array}{c}\mathrm{n}^{\circ}{ }^{\circ} \text { cantiga } \\
\text { en el ms. }\end{array}$ & $\begin{array}{c}\text { folio / } \\
\text { columna }\end{array}$ & \multicolumn{1}{|c|}{ Incipit } & Género & Modalidad \\
\hline 150,2 & 936 & $\begin{array}{l}200 \mathrm{v} / \mathrm{b} \\
201 \mathrm{r} / \mathrm{a}\end{array}$ & Amiga ben Jey domeu amigo & Amigo & Refrán \\
\hline 150,3 & 937 & $201 \mathrm{r} / \mathrm{a}$ & Amiga domeu amigo & Amigo & Refrán \\
\hline 150,5 & 938 & $201 \mathrm{r} / \mathrm{ab}$ & Hiru ${ }_{9}$ queredes ay meu amigo & Amigo & Refrán \\
\hline 150,7 & 939 & $\begin{array}{l}201 \mathrm{r} / \mathrm{b} \\
201 \mathrm{v} / \mathrm{a}\end{array}$ & Que muy gram tortomı fez amiga & Amigo & Refrán \\
\hline 150,4 & 940 & $201 \mathrm{v} / \mathrm{a}$ & En outro dia en Jan Jaluador & Amigo & Refrán \\
\hline 150,6 & 941 & $201 \mathrm{v} / \mathrm{ab}$ & Muyta tendi en ben da mha senhor & Amor & Refrán \\
\hline
\end{tabular}

Tabla 1. Cantigas atribuidas a Sancho Sanchez, clérigo en $B$

\begin{tabular}{|l|l|l|l|l|l|}
\hline $\begin{array}{l}\text { n. }{ }^{\circ} \text { cantiga } \\
\text { en } M e d D B\end{array}$ & $\begin{array}{c}\text { n. }{ }^{\circ} \text { cantiga } \\
\text { en el ms. }\end{array}$ & $\begin{array}{c}\text { folio / } \\
\text { columna }\end{array}$ & \multicolumn{1}{|c|}{ Incipit } & Género & Modalidad \\
\hline 150,2 & 524 & $83 \mathrm{v} / \mathrm{a}$ & Amiga ben Jey domeu amigo & Amigo & Refrán \\
\hline 150,3 & 525 & $83 \mathrm{v} / \mathrm{ab}$ & Amiga domeu amigo & Amigo & Refrán \\
\hline 150,5 & 526 & $83 \mathrm{v} / \mathrm{b}$ & Huru $_{9}$ quereds ay meu amigo & Amigo & Refrán \\
\hline 150,7 & 527 & $83 \mathrm{v} / \mathrm{b}$ & Que muy gram torto mi fez amiga & Amigo & Refrán \\
\hline 150,4 & 528 & $84 \mathrm{r} / \mathrm{a}$ & En outro dia en san saluador & Amigo & Refrán \\
\hline 150,6 & 529 & $84 \mathrm{r} / \mathrm{b}$ & Muyta tendi eu ben da mha senhor & Amor & Refrán \\
\hline
\end{tabular}

Tabla 2. Cantigas atribuidas a Sancho Sanchez, clérigo en $V$

Incluso con una lectura superficial de la información aducida, es fácil comprobar como el orden de las cantigas es idéntico en ambos apógrafos. No obstante, una lectura atenta de cada una de las composiciones permite engarzar de otro modo los hechos cantados en cada texto. Esa relación entre composiciones permite ver una progresión narrativa, que se vuelve diáfana una vez que se modifica el orden en el que $B$ y $V$ han transmitido dichos textos.

Además, del mismo modo que ocurre en el cancionero de Johan Nunez Camanez -en el que las cinco cantigas de amigo y las tres cantigas de amor se integran en una "“novella" in versi, o meglio nel breve poemetto, forse incompleto e frammentario, risultante dal riordinamento delle otto liriche $\rangle^{51}-$, en la secuencia que ahora

explicados en Miguel Á. Pousada Cruz, art. cit., [p. 3]. Las primera columna de ambas tablas recoge el número que presentan las cantigas objeto de estudio en MedDB - Base de datos de la Lírica Profana Galego-Portuguesa, versión 2.3.3, del Centro Ramón Piñeiro para a Investigación en Humanidades [accesible desde <http://www.cirp.es/pls/bdo2/f?p=MEDDB2>; 12/2014].

${ }^{51}$ Giuseppe Tavani, «Il canzoniere di Joam Nunes Camanês», AION, II/2 (1960), pp. 47-70 [p. 48]. 
estudiamos entran en juego las cinco composiciones de amigo y la cantiga de amor, que podrían ser reordenados de este modo ${ }^{52}$ :

$$
\text { I }(150,6)
$$

Muit' atendi eu ben da mia senhor e ela nunca me quis [ben] fazer, e eu non tenho i al, senon morrer, pois que m' ela non val, nen seu amor, mais Deus, que sabe ben que est' assi, pois eu morrer, demande-lho por min.

Servi-a sempre mui de coraçon en quanto pudi, segundo meu sén, e ela nunca me quis fazer ben e eu non tenho i al, se morrer non, mais Deus, que sabe ben que est'assi, pois eu morrer, demande-lho por min.

Servi-a sempre, non catei por al des que a vi, e sempre aver cuidei algun ben dela, mais ben vej' e sei que morte tenh' $i$, pois que me non val; mais Deus, que sabe [be]n que est'assi, pois eu morrer, demande-lho por min.

La «historia» se abre con el lamento típico del joven enamorado que espera alcanzar alguna recompensa de la senhor a la que sirve. Como es habitual, de ella no obtiene más que indiferencia. Esta no correspondencia de la dama causa en él un sentimiento de desasosiego tan grande que no ve otra solución a su coita que la misma muerte. Los versos de refrán repiten a lo largo de toda la cantiga que sea el mismo Dios el que, tras la muerte del servidor, pida a la dama el galardón que en vida no le quiso ofrecer al enamorado. La cantiga, como puede observarse, incide en el hecho de que él siempre cumplió de la mejor manera posible-segundo meu sén (v.7)-con su servicio -Servi-a sempre mui de coraçon / en quanto pudi (v. 7-8), Servi-a sempre (v. 13)- y con sus obligaciones -non catei por al I des que a vi (v. 13-14)- y, como tal, esperó pacientemente alguna recompensa-Muit'atendi eu ben da mia senhor (v. 1), e sempre aver cuidei / algun ben dela (vv. 14-15)-. La actitud impasible de su senhor es clara a lo largo de toda la composición - e ela nunca me quis [ben] fazer (v. 2), pois que m'ela non val, nen seu amor (v. 4),e

${ }^{52} \mathrm{La}$ lectura de los textos que aportamos en este epígrafe del trabajo ha sido tomada de la edición de Miguel Á. Pousada Cruz, «Las cantigas de Sancho Sanchez, clérigo», art. cit. 
ela nunca me quis fazer ben (v. 9), pois que me non val (v. 16)-, del mismo modo que el joven es consciente de su sufrimiento - e eu non tenho i al, senon morrer (v. 10), mais ben vej'e sei / que morte tenh' $i$ (vv. 15-16)-. La cantiga de amor sirve, por tanto, para introducir la perspectiva del enamorado sobre la relación amorosa. Veamos, a continuación, la visión que la dama tiene de esa misma relación.

$$
\text { II }(150,4)
$$

En outro dia, en San Salvador, vi meu amigo, que mi gran ben quer, e nunca máis coitada foi molher do que eu lh'i fui, segundo meu sén, cuidand', amiga, qual era melhor: de o matar ou de lhi fazer ben.

El é por mi tan coitado d' amor que morrerá, se meu ben non ouver, e vi-o eu ali. E, como quer que vos diga, ouvi a morrer por én, cuidand', amiga, qual era melhor: [de o matar ou de lhi fazer ben.]

Meu é o poder, que sõo senhor, de fazer del o que m' a mí prouguer, mais foi i tan coitado que mester non m' én fora, pois que o vi, per ren, cuidand', amiga, qual era [melhor: de o matar ou de lhi fazer ben.]

La segunda cantiga de la secuencia presenta a la joven enamorada en un escenario que vincula esta composición de Sancho Sanchez con las cantigas de santuario típicas del corpus de amigo gallegoportugués. No obstante, para entender dicha cantiga como parte de esa clasificación simplemente disponemos de la presencia del hagiotopónimo San Salvador que, según los recientes descubrimientos documentales sobre nuestro autor realizados por José A. Souto Cabo, podría corresponderse con la antigua parroquia de San Salvador de Bastavales ${ }^{53}$. La joven relata a una amiga, que actúa en silencio como confidente -véase el apóstrofe del primer verso de refrán de cada cobra o la expresión como quer / que vos diga (vv. 9-10)-, el encuentro con su amigo -vi meu amigo (v. 2), e vi-o eu ali (v. 9), pois que o vi (v. 16)-, hace pocos días -En outro dia (v. 1)-, cerca del entorno del santuario de San Salvador. Del mismo modo que sucedía

${ }^{53}$ José António Souto Cabo, cap. cit., p. 781. 
en I $(150,6)$-donde el enamorado decía estar experimentando un terrible sufrimiento derivado de la no correspondencia de la dama a su realizado y diligente servicio-, en esta cantiga la joven enamorada confiesa a su confidente lo confundida que se halló y el sufrimiento que experimentó en aquella situación, en aquel momento próximo en el tiempo, pero indeterminado, y en aquel lugar exacto -e nunca máis coitada foi molher / do qu'eu lh'i fui (vv. 3-4), ouvi a morrer por én (v. 10)-, al no saber cómo debería haber actuado: ¿debería haber causado algún mal a su amigo o, por el contrario, debería haberlo recompensado por su servicio amoroso? -cuindand', amiga, qual era melhor: / de o matar ou de lhi fazer ben (vv. 5-6, 11-12 y 17-18)-. El sufrimiento que ella padece es generado por la indecisión que oscila entre esos dos polos totalmente opuestos y que, en cierto sentido, contraponen la actitud característica de la senhor a la de la amiga. Además, llama la atención lo consciente que es de toda la situación amorosa: le cuenta todo lo sucedido a su confidente y emplea las mismas palabras que el amante en la cantiga de amor $-s e-$ gundo meu sén (v. 4)-; conoce perfectamente el estado de sufrimiento amoroso en el que él se encuentra-que mi gran ben quer (v. 2), El é por mi tan coitado d'amor (v. 7), foi i tan coitado (v. 15)-; sabe que no recompensar su servicio amoroso es lo que más daño puede causarle-morrerá, se meu ben non ouver (v. 8)-; y, sobre todo, conoce su posición privilegiada en el tablero de juego-Meu é o poder, que sõo senhor, / de fazer del o que m'a mí prouguer (vv.13-14)-. A pesar de su actitud altiva, desde su papel de senhor, la joven confiesa a su amiga que el abatimiento de su amigo fue, en aquel lugar próximo al santuario, tan grande que no consideró oportuno causarle ningún mal -mais foi i tan coitado que mester / non m'én fora, pois que o vi, per ren (vv. 15-16)-. No obstante, tampoco especifica en esta cantiga que lo haya recompensado, aunque parece que las cosas empiezan a cambiar en el momento en el que la protagonista de la historia abandona el papel de senhor para aceptar la actitud propia de una amiga enamorada ${ }^{54}$.

Como se puede advertir, las piezas del puzzle empiezan a encajar en el marco de esta historia. Por un lado, nos encontramos ante un enamorado afligido que sufre por la no correspondencia de su dama a su servicio amoroso y que ve en la muerte su única salvación. En el otro lado del campo de batalla, presenciamos la actitud rígida y altiva de una senhor que es consciente de su posición en el juego amoroso -declara explícitamente que es ella quien detenta el poder-, y que aun conociendo el sufrimiento del joven que la sirve, permanece estática ante el mismo y no parece querer recompensarlo, al menos, en un principio.

\footnotetext{
${ }^{54}$ Para un análisis de este doble comportamiento de la protagonista de las cantigas de amigo, puede verse Mercedes Brea, «L'amiga et la senhor dans les cantigas de amigo», Textuel, 49 (2006), pp. 49-103.
} 
III $(150,5)$

Ir-vos queredes, ai, meu amigo, [i], e pesa-m'end', assi me valha Deus, e pesa-mi por estes olhos meus e porque sei que viverei assi, como vive quen á coita d'amor e non á de si, nen de ren, sabor.

Des u vos fordes, ja i al non á, por Deus, amigo, mais eu que farei? Ca outro conselh'eu de min non sei, senon viver eu, quanto viver ja, como vive quen á coita [d'amor e non á de si, nen de ren, sabor].

Esta [i]d', amigo, tan grave m'é que vo-lo non saberia dizer, mais pois end'al ja non pode seer, se viver, viverei, per bõa fe, como vive quen á coita d'amor [e non á de si, nen de ren, sabor].

La tercera composición de la secuencia presenta un estado más avanzado de la historia sentimental. Algo ha fraguado entre los dos personajes principales. Aparece un elemento desestabilizador, un gran conflicto: el joven desea o se ve en la obligación de partir. Nótese que no se dice la causa, pero tampoco parece importante para el desarrollo de la progresión narrativa. La joven enamorada se dirige a su amigo para expresar su sufrimiento ante este hecho y lo hace desde una posición de igual a igual; ya no se muestra distante, más bien se declara coitada de amor. La joven se encarga de recordarle continuamente el origen de su turbación y lo hace siempre en el verso inicial de cada cobra-Ir-vos queredes, ai meu, amigo, [i] (v. 1), Des u vos fordes (v. 7), Esta [i]d', amigo, tan grave m'é (v. 13)-. Además, los versos de refrán condensan la coita de amor en la que se encuentra -como vive quen á coita de amor / e non á de si, nen de ren, sabor (vv. 5-6, 11-12, 17-18)-, con lo que cada estrofa recoge la espiral de sufrimiento en la que la amiga ha caído. Nuevamente, es consciente de todo: sabe que tendrá que vivir $-e$ porque sei que vivirei assi (v. 4), senon viver eu, como viver ja (v. 10), se viver, viverei, per boa fe (v. 16)-como lo hace quien tiene mal de amor, es decir, sin hallar placer ni en sí mismo ni en ninguna otra cosa. Llega incluso a resignarse y a aceptar la situación cuando expresa mais pois end'al ja non pode seer / se viver, viverei, per bõa fe (vv. 15-16). 
La carga emocional de la composición es enorme desde el primer verso al último, hasta el punto de transmitir la angustia que experimenta la joven enamorada: la repetición del verbo pesar (vv. 2 y 3 ), la búsqueda inútil del consuelo divino (vv. 2 y 8 ) que no calmará su dolor, el hecho de no encontrar una solución propia a su fuente de tristeza -por Deus, amigo, mais eu que farei? (v. 8), Ca outro conselh' eu de min non sei (v. 9)-y, por último, la inefabilidad del propio problema Esta [i]d', amigo, tan grave m'é / que vo-lo non saberia dizer (vv. 13-14) son los recursos empleados para expresar esta terrible coita de amor.

$$
\operatorname{IV}(150,7)
$$

Que mui gran torto mi fez, amiga, meu amigo, quando se foi d'aqui a meu pesar, pois que lho defendi, mais pero queredes que vos diga? Se veess'én, ja lh'eu perdoaria.

Tanto mi fez gran pesar sobejo en s'ir d'aqui, que ouve de jurar, mentre vivesse, de lhi non falar, mais, porque tan muito [o] desejo, se veess'én, ja lh'eu perdoaria.

Ben vos dig', amiga, en verdade, que jurei de nunca lhi fazer ben ant'el, e non leixou de s'ir por én, mais, porque ei del gran soidade, se veess'én, [ja lh'eu perdoaria.]

La cuarta composición presenta a la joven enamorada hablando con una confidente. El joven ya ha partido y, en consecuencia, la senhor todopoderosa que veíamos en II $(150,4)$ relata a su amiga lo enfadada que se encuentra por a la marcha del amigo-quando se foi d'aqui / a meu pesar (vv. 2-3), en s'ir d'aqui (v. 7)-. El dolor causado se expresa en los versos iniciales de la primera y de la segunda estrofas -Que mui gran torto mi fez, amiga, / meu amigo (vv. 1 y 2), Tanto mi fez gran pesar sobejo (v. 6)-. La sanha vuelve a aparecer en la protagonista de la composición. Se siente molesta con la marcha del amigo. Llega a afirmar, en la primera cobra, que le prohibió partir - pois que lho defendi (v. 3)-, en la segunda, que le juró no volver a hablarle mientras viviese -ouve de jurar, / mentre vivesse, de lhi non falar (vv. 7 y 8)- y, en la tercera, que juró en su presencia que nunca lo recompensaría -que jurei de nunca lhi fazer ben / ant'el, e non leixou de s'ir por én (vv. 12-13)-. A pesar de todos sus 
«chantajes», tal y como ella confirma, él no cejó en su empeño de partir - e non leixou de s'ir por én (v. 13)-.

Aunque se muestra sanhuda y molesta con el enamorado, la cantiga presenta una serie de razones que demuestran, en todo caso, que está profundamente enamorada $\mathrm{y}$, en consecuencia, que, por muy enfadada que esté, no tendría ningún problema en cumplir con la condición, expresada en el verso de refrán, de perdonar a su amigo -se veess'én, já lh'eu perdoaria (vv. 5, 10 y 15)-. La protagonista confiesa a la confidente, que, si él vuelve y puesto que tanto lo ama -porque tan muito [o] desejo (v. 9)- y que siente por él una gran nostalgia-porque ei del gran soidade (v. 14)-, a pesar de los pesares sufridos, ella lo perdonaría. La situación narrativa queda, por tanto, en suspense para el público: ¿Regresará el enamorado?¿Podrá la joven, como dice, perdonarlo?

$$
\mathrm{V}(150,2)
$$

Amiga, ben sei do meu amigo que é mort'ou quer outra dona ben, ca non m'envia mandado nen vén, e, quando se foi, posera migo que se veesse logo a seu grado, se non, que m'enviasse mandado.

A min pesou muito quando s'ia e comecei-lhi enton a preguntar: -Cuidades muit', amig', alá morar? E jurou-mi par Santa Maria que se [veesse logo a seu grado, se non, que m'enviasse mandado].

U estava conmigo falando, dixi-lho:-Que farei, se vos non vir ou se vosso mandado non oir ced'? [E] enton jurou-m'el, chorando, que se [veesse logo a seu grado, se non, que m'enviasse mandado].

Nuevamente encontramos a la joven que se dirige a una amiga para expresarle sus inquietudes. Si en la cantiga anterior mostraba su enfado ante la partida no deseada de su amigo, en esta composición se observa que el joven no solo no ha regresado sino que no le ha enviado ninguna noticia ni aviso de su regreso - ca non m'envia mandado nen vén (v. 3)-. La desesperación de la joven es patente y plantea a su confidente dos posibles causas de este silencio: o bien su 
amigo ha muerto o bien está al servicio de otra senhor-Amiga, ben sei do meu amigo / que é mort'ou quer outra dona ben (vv. 1-2)-.

Su turbación es lógica, pues el joven, antes de partir, había acordado con ella -e, quando se foi, posera migo (v. 4), E jurou-mi par Santa Maria (v. 10), [E] enton jurou-m'el, chorando (v. 16)- que regresaría pronto con mucho gusto o, en todo caso, le haría llegar un mensaje, tal y como recogen los versos de refrán -que se veese logo a seu grado / se non, que m'enviasse mandado (vv. 5-6, 11-12 y 17-18)-.

El dolor ante la partida del enamorado vuelve a aparecer en esta composición, hasta el punto de traer al presente del diálogo entre la joven y su confidente, el discurso directo que la dolida enamorada mantuvo con el amigo en el momento previo a su marcha $-A$ min pesou muito quando s'ia / e comecei-lhi enton a preguntar (vv. 7-8), U estava comigo falando, / dixi-lho (vv. 13-14)-. La joven repite las palabras exactas que dedicó a su enamorado cuando este la informó sobre su ida -Cuidades muit', amig', alá morar? (v. 9)- y vuelve a mencionar el hecho de que, en aquel preciso momento, le transmitió que no sabría cómo actuar ante su falta-Que farei, se vos non vir / ou se vosso mandado non oir / ced'? (vv. 14-16)-, como ya había señalado en III $(150,5)$. Nótese que en esta composición sí se destaca que el enamorado también sufre por el hecho de tener que partir -[E] enton jurou-m'el, chorando (v. 16)-. Podemos ver, por tanto, como la situación descrita en esta secuencia se va completando con elementos tomados de las diferentes cantigas que participan en esta progresión narrativa.

VI $(150,3)$

Amiga, do meu amigo

[o]i eu oje recado, que é viv' e namorado doutra dona, ben vos digo, mais jur'a Deus que quisera oir ante que mort'era!

Eu era maravilhada porque tan muito tardava, pero sempr' esto cuidava, se eu del seja vingada, mais jur'a Deus que quisera [oir ante que mort' era!]

Mui coitada per-vevia, mais ora non sei que seja de min, pois outra deseja 
e leixou min que servia, mais jur' a Deus que quisera

[oir ante que mort' era!]

E a el mui melhor era

e a min mais mi prouguera!

La historia se cerraría con esta composición, en la que se cuenta el desenlace de esta fallida relación. La joven enamorada, llena de sanha, indica a su amiga confidente que ha recibido noticias sobre su amigo-Amiga, do meu amigo / [o] i eu oje recado (vv. 1 y 2)-. El bivium de posibilidades - Amiga, ben sei do meu amigo / que é mort'ou quer outra dona ben (v. 1-2, cantiga 150,2)- que ella planteaba en la anterior composición se ha disipado, cumpliéndose así sus temores: é viv'e namorado / doutra dona (vv. 3 y 4), pois outra deseja (v. 15).

La larga espera-Eu era maravilhada / porque tan muito tardava (vv. 7 y 8)-que había generado en ella un sufrimiento terrible deja paso, en esta composición final, a una nueva coita de amor $-M u i$ cuitada per-vevia / mais ora non sei que seja / de min (vv. 13-15)-, ya no provocada por el sentimiento de saudade ante la partida del amigo, sino por el cambio de senhor - pois outra deseja / e leixou min que servia (vv. 15 y 16)-. El dolor de la joven es tan grande que solo puede desear para su amigo la muerte y lo hace en los versos de refrán -mais jur'a Deus que quisera / oir ante que mort'era (vv. 5-6, 11-12 y 17-18)-.

La secuencia se cierra con los dos versos finales de la finda en los que la joven sentencia que morir sería para su amigo la mejor solución y para ella la opción más reconfortante ante este desenlace inesperado -E a el mui melhor era / e a min mais mi prouguera! (vv. 19-20)-. De estos dos versos conclusivos y llenos de una gran carga emocional puede deducirse un regreso de la joven amiga a la actitud inicial de senhor, previa al enamoramiento profundo expresado desde III $(150,5)$, y un gran rencor ante el doloroso final.

Dentro del cancionero de amigo gallego-portugués, la actitud que muestra el personaje protagonista femenino oscila entre el rol de la amiga ingenua -que expresa sufrimiento, enfado o emoción en el marco de la relación con el joven-y el rol de la senhor consciente de su superioridad. La secuencia lírico-narrativa que puede encontrarse en el corpus de Sancho Sanchez, presenta, en las composiciones de este género, el segundo rol al que nos acabamos de referir; los versos «Meu é o poder, que sõo senhor, / de fazer del o que m' a mí prouguer» de II $(150,4)$ son una buena muestra de esto. Como puede observarse, la visión que el amigo aporta del mismo hecho sentimental en I $(150,6)$ es típica de las cantigas de amor. La historia de amor se inicia in media res: es posible deducir con cierta facilidad que el encuentro en el entorno de San Salvador de II $(150,4)$ no ha sido el 
primero de la pareja. A medida que la joven se enamora, su personaje oscila desde una posición altiva-Meu é o poder, que sõo senhor I de fazer del o que m'a mí prouguer (vv. 13-14, cantiga 150,4), cuidand', amiga, qual era melhor: / de o matar ou de lhi fazer ben (vv. 5-6, 11-12 y 17-18, cantiga 150,4)- a una situación de enamoramiento, en la que se percibe que sufre también coita de amor. El amigo anuncia su partida. El desasosiego que presenta la amiga ante esta inesperada situación es tan grande que la pareja pacta que él deberá enviar alguna noticia, si algo impide su pronto regreso -III $(150,5)$ - La tristeza y el desasosiego aumentan y la joven necesita desahogar sus penas con una amiga confidente (siempre silente y anónima) -IV $(150,7)-$. La demora y la falta de noticias genera en la joven senhor incertidumbres y miedos que serán compartidos con una amiga confidente: ¿Estará muerto?¿Estará enamorado de otra senhor? -V (150,2)-. Finalmente, las dudas desaparecen: el amigo sigue vivo y sirve a otra senhor. La ira y el rencor vuelven al discurso de la joven -VI $(150,3)$-.

La progresión narrativa presente en las cantigas del clérigo Sancho Sanchez puede ser apoyada también en la presencia de determinados elementos intratextuales empleados a lo largo de las distintas composiciones del autor. Si bien dichos elementos forman parte del acervo común de la lírica trovadoresca gallego-portuguesa, en el caso que ahora se analiza, permiten establecer relaciones entre los textos examinados y, en última instancia, aportan una mayor cohesión textual que permite crear puentes entre las distintas composiciones que forman esta fallida «historia» de amor. Nos referimos a las siguientes iteraciones: 1) segundo meu sén, en posición de rima: I (v. 8) y II (v. 4); 2) fazer ben, en posición de rima: I (v. 9), II (v. 12) y III (v. 12); 3) senhor, en posición de rima: I (v. 1) y II (v.13); 4) amor, en posición de rima: I (v. 4), II (v.7) y III (vv. 5, 11 y 17); y 5) que farei: III (v. 8) y V (v. 4). También llaman la atención las siguientes estructuras bimembres: mort'ou quer, en V (v. 2), y viv'e namorado, en VI (v. 3). La expresión de la partida del joven con el verbo $i r$-o con sus derivados- que aparecen en III (vv. 1, 7 y 13), IV (vv. 2, 7 y 13) y V (v. 4). La expresión del sufrimiento de los amantes empleando formas conjugadas del verbo pesar (o su sustantivo) aparece a lo largo del corpus en III (vv. 2 y 3), IV (v. 6) y en V (v. 7). Del mismo modo, podrían relacionarse las formas recado, recogidas en V (vv. 3, 6, 12, 15 y 18), y mandado, en VI (v. 2).

\section{A MODO DE CONCLUSIÓN}

Como hemos intentado mostrar a lo largo de este trabajo, la presencia de grupos de cantigas que presentan una posible progresión o secuencia lírico-narrativa no ha pasado desapercibida a la crítica. Como se ha señalado, ya sea desde los trabajos generales -como 
los de Diez o Jeanroy-, ya sea desde trabajos individuales sobre cancioneros, cantigas o autores concretos realizados por prestigiosos investigadores -como Tavani-, esta cuestión ha sido tratada en numerosas ocasiones. A pesar de que la aceptación o no de dichas secuencias es algo relativamente subjetivo, debe subrayarse el hecho de que diversos autores y editores las hayan señalado. Del mismo modo, cabe destacar que importantes críticos y conocedores de la lírica trovadoresca gallego-portuguesa, como Carolina Michaëlis de Vasconcelos o Isabel Pope, negaron la existencia de algunas secuencias aceptadas por otros investigadores o propusieron analizar este hecho desde otra perspectiva, interpretando esas progresiones narrativas como variaciones diversas de un tema o de un escenario escogido por un determinado trovador o juglar.

La existencia de diversos ciclos temáticos dentro de las cantigas de escarnho -por ejemplo, el ciclo das amas contra Johan Soarez Coelho, el vilipendio a Maria Balteira, el ciclo de Fernan Diaz, los falsos cruzados...-, la existencia de núcleos narrativos claros en las composiciones atribuidas a un determinado autor, sea cual sea su género poético-musical, $v$. gr. en los cancioneros de Martin Codax o Fernan Velho, demuestran que el engarce entre composiciones es posible y parece que estaba presente dentro de los límites impuestos por los cánones poéticos fijados para la lírica profana gallego-portuguesa.

No obstante, no nos resulta posible afirmar, con los hechos analizados, que estas composiciones pudiesen estar pensadas para ser interpretadas en conjunto, como tampoco podemos asegurar que estas secuencias sean las más antiguas de toda la lírica románica medieval.

Como hemos visto para el corpus de Sancho Sanchez, el orden de las secuencias podría ser distinto al que han transmitido los cancioneros. Esto dificulta, aún más, la identificación de dichos núcleos narrativos y, al mismo tiempo, podría ser un indicio de la posible intervención, o no, del autor en la ordenación de las composiciones pertenecientes a su respectivo cancionero -hipótesis que parece sustentarse en el hecho de que las cantigas de Martin Codax presenten el mismo orden en $N$ (Pergamino Vindel) y en $B$ y $V-$, lo que permitiría deducir que, al menos, en última instancia, tal orden se debe a una intervención previa -nada indica que haya sido realizada por el mismo autor-a la de los compiladores de los manuscritos derivados de la rama $\alpha^{55}$.

La presencia de cantigas de amor de determinados autores que entran en relación dialógica con las cantigas de amigo -y viceversa- indica que estas progresiones narrativas no se circunscriben

${ }^{55}$ Véase a este respecto, Vicenç Beltran, art. cit. 
solamente al género de amigo ${ }^{56}$. No obstante, parece que el número de composiciones de amigo engarzadas entre sí es mayor al del otro género amoroso. Además, debe destacarse que las cantigas de santuario parecen presentar una mayor progresión narrativa que otras subcategorías o motivos dentro del corpus de amigo. Las cantigas de escarnho e maldizer, por su parte, se circunscriben a «ciclos temáticos» en torno a un tema o personaje, más que a progresiones de este tipo.

Resulta difícil discernir, en algunas ocasiones, la diferencia entre variaciones de un motivo concreto (o de una determinada situación) y progresión o secuencia (lírico-)narrativa. Del mismo modo, nada permite confirmar, hasta el momento, que las cantigas que presentan una secuenciación de estas características se vinculen a un grupo concreto de autores o a una determinada época.

En cualquier caso, el conjunto de composiciones conservadas de Sancho Sanchez muestra un engarce de distintas emociones que parecen mantener entre ellas algún vínculo: la coita del enamorado (I) es causada por el desdén o la indiferencia de la dama, que cambia de actitud cuando es ella misma la que experimenta esa coita de amor que no le permite decidir qué hacer con el amigo (II), una indecisión y un pesar irritados por el anuncio de una partida que le resulta tan grave (III), pero que no le impiden mostrarse propicia al perdón (e incluso a otorgarle el ben que le requería) si su amado -del que siente soidade-vuelve a su lado (IV). La tardanza en el regreso solo puede provocar inquietud y una profunda desazón: si le juró que volvería pronto o, en caso de no poder hacerlo, que le enviaría noticias, y no lo hace, quiere decir que o está muerto o «quer outra dona ben» $(\mathrm{V})$; la confirmación de la segunda opción despierta en ella una ira tan fuerte que anhela ser vingada y le complacería verlo muerto (VI).

\footnotetext{
${ }^{56}$ Para ampliar más información sobre esta cuestión, véase Mercedes Brea y Pilar Lorenzo Gradín, op. cit., pp. 70-74 y Mercedes Brea, «El diálogo entre los dos géneros amorosos de la lírica gallego-portuguesa», Estudios Románicos, vol. 16-17 (2007-2008), pp. 267-283 [p. 282].
} 


\section{$\cos$}

A VUELTAS CON LA PROGRESIÓN NARRATIVA EN LA LÍRICA GALLEGO-PORTUGUESA. ¿UNA SECUENCIA EN LAS CANTIGAS DE SANCHO SANCHEZ, CLÉRIGO?

RESUMEN: Los apógrafos renacentistas $B$ y $V$ conservan un conjunto de cinco cantigas de amigo y una cantiga de amor que son atribuidas, a la luz de las rúbricas atributivas y de la Tavola colocciana, al clérigo Sancho Sanchez. En este trabajo se analiza la posible existencia de una secuencia narrativa entre esas seis composiciones, tras una lectura y un atento análisis de los textos.

Palabras ClaVe: Sancho Sanchez, clérigo, secuencia narrativa, secuencia lírica, progresión narrativa, lírica profana gallego-portuguesa.

\section{RETHINKING THE NARRATIVE PROGRESSION IN GALICIAN- PORTUGUESE LYRIC POETRY. IS THERE A SEQUENCE IN THE CANTIGAS BY SANCHO SANCHEZ, CLÉRIGO?}

AbSTRACT: The Renaissance apographs $B$ and $V$ preserve a collection of five cantigas de amigo and a cantiga de amor attributed to the clergyman Sancho Sanchez, in the light of the identifying rubrics and the tavola by Colocci. The aim of this paper is to analyze the possible existence of a narrative sequence among the aforementioned six verses, following a detailed reading and examination of the poems.

Keywords: Sancho Sanchez, clérigo, narrative sequence, lyric sequence, narrative progression, Galician-Portuguese prophane lyric poetry. 